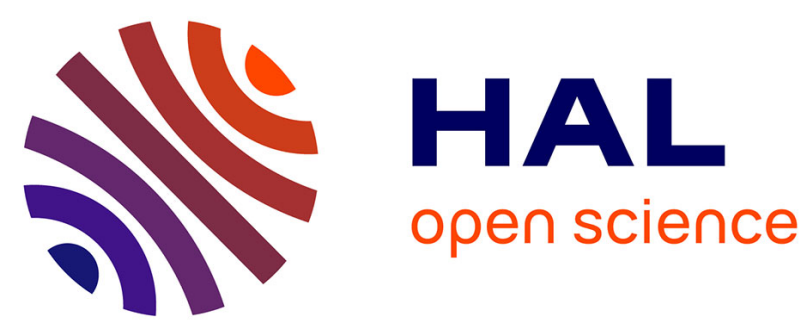

\title{
On-board phthalocyanine gas sensor microsystem dedicated to the monitoring of oxidising gases level in passenger compartments
}

Jérôme Brunet, Alain Pauly, Christelle Varenne, Bernard Lauron

\section{- To cite this version:}

Jérôme Brunet, Alain Pauly, Christelle Varenne, Bernard Lauron. On-board phthalocyanine gas sensor microsystem dedicated to the monitoring of oxidising gases level in passenger compartments. Sensors and Actuators B: Chemical, 2008, 130 (2), pp.908-916. 10.1016/j.snb.2007.10.074 . hal-00282421

\section{HAL Id: hal-00282421 \\ https://hal.science/hal-00282421}

Submitted on 27 May 2008

HAL is a multi-disciplinary open access archive for the deposit and dissemination of scientific research documents, whether they are published or not. The documents may come from teaching and research institutions in France or abroad, or from public or private research centers.
L'archive ouverte pluridisciplinaire HAL, est destinée au dépôt et à la diffusion de documents scientifiques de niveau recherche, publiés ou non, émanant des établissements d'enseignement et de recherche français ou étrangers, des laboratoires publics ou privés. 


\title{
On-board phthalocyanine gas sensor microsystem dedicated to the monitoring of oxidising gases level in passenger compartments.
}

\author{
J. Brunet ${ }^{*}$ A. Pauly, C. Varenne, B. Lauron \\ LASMEA (UMR 6602 du CNRS), Université Blaise Pascal, CLERMONT-FERRAND II, \\ 24, Avenue des Landais 63177 AUBIERE Cedex, France.
}

\begin{abstract}
The monitoring of in-vehicle pollutant concentrations by means of an on-board molecular semiconductor gas sensor microsystem is described in this paper. The main objective is to measure in real time with a high level of accuracy the variations of oxidising gases concentration in bus passenger compartments to inform travellers or commuters and to evaluate the assessment of bus drivers' exposure. A self-contained gas sensor microsystem of which the sensitive element is constituted by a thin layer of copper phthalocyanine has been developed, validated at laboratory under controlled experimental conditions and then implemented in a bus of the urban network of Clermont-Ferrand, France. Preliminary in-car measurements realized with commercial analyzers show that nitrogen dioxide is the major oxidising gas present on urban roads and so is considered as the target gas in this study. Tests realized under artificially polluted atmosphere show the high performances obtained with our microsystem, such as high resolution, low threshold, good reproducibility, satisfying concentration range and real time detection. The calibration curve has been determined at laboratory by experiments made under low $\mathrm{NO}_{2}$ concentrations in the range of those measured in urban atmosphere. The relation between sensor microsystem response and gas concentration is established with accuracy. The validation of our microsystem is illustrated by measurements realized under real conditions, i.e. in an urban bus. It shows that $\mathrm{NO}_{2}$ concentration variations are mainly correlated with the nature of roads and that rates of pollutant measured in traffic are always greater than those measured by the nearest stations of the air quality control network.
\end{abstract}


Keywords: on-board sensor, gas sensor microsystem, copper phthalocyanine, nitrogen dioxide, pollutant monitoring.

* Corresponding author. Tel : 33-473-407247; Fax : 33-473-407340

E-mail : brunet@lasmea.univ-bpclermont.fr

\section{Introduction}

Besides the reduction of gases responsible for the greenhouse effect, the air quality improvement in industrialized cities by the decrease in urban pollutant concentrations is also a worldwide preoccupation. This growing awareness is enhanced by the fact that atmospheric pollution is not only an environmental problem but induces serious health hazards on humans, too. In urban context, all city-dwellers suffer from health problems induced by pollutants. Nevertheless, we must distinguish two types of exposure: (1) the nonoccupational exposure which mainly affects pedestrians, cyclists, motorcyclists, car drivers, commuters, and street residents [1-9], and (2) the occupational exposure which concerns taxi, bus and truck drivers but also postmen or city sweepers [10-14]. Let's notice that these professional groups are especially exposed because they are affected by urban pollution in nonoccupational context, too.

Amongst all pollutants, nitrogen dioxide is a major problem in urban areas. This primary pollutant is highly concentrated in downtown and contributes to the formation of another toxic gas: ozone. Moreover, this gaseous species has very harmful effects on human health. Indeed, as low as $15 \mathrm{ppb}$, nasal irritations, eyes irritations and cough are associated to $\mathrm{NO}_{2}$ exposure. For $30 \mathrm{ppb}$, hyperactivity of airway muscles appears. Above $80 \mathrm{ppb}$, some researches report an increased incidence of respiratory infections and sore throats [15]. The guidelines for nitrogen dioxide given by the World Health Organization (WHO) are $100 \mathrm{ppb}$ for one hour and $75 \mathrm{ppb}$ per day. In urban environment, these values can be greatly exceeded especially during unusual driving condition periods. So, for public protection, this gas needs to be continuously monitored. 
To inform people about the quality of the air they breathe and to protect them from pollution episodes, local networks of air quality control have been set up like the AtMO network, in France. Gaseous and particular pollutants are monitored continuously by commercial gas analyzers implemented in fixed and air-conditioned stations at rural and urban places. These stations not being located on the roads, the concentrations measured for primary pollutants such as $\mathrm{NO}_{2}$ are often lower than those really present in the traffic $[1,5,6,10,12,13,16]$. So, to avoid any underestimation of the real exposure of commuters or drivers, it is judicious and more efficient to realize in-vehicle measurements.

Most studies dedicated to the determination of occupational and nonoccupational exposures to traffic-related pollutants such as $\mathrm{NO}_{\mathrm{X}}, \mathrm{CO}$, VOCs or hydrocarbons have been realized by means of passive samplers $[4,6,11,13]$ or commercial spectroscopic gas analyzers $[8,10,12$,$] . Passive samplers evaluate gas concentrations for several hours or days of exposure$ and are not able to deliver real time results. So, they are not appropriated for permanent monitoring of pollutants. As for gas analyzers, their high dimensions, low mechanical vibration tolerance, high energy consumption and necessity to be maintained at wellcontrolled temperature make them not suitable as on-board pollutant monitoring systems. Because of their low dimensions, low consumption powers, high level of mobility, electric output signal easily exploited by on-board electronic systems and ability to deliver real time response, gas microsensors are perfectly suitable for such an application.

This article deals with an on-board and self-contained gas sensor microsystem for the continuous and real time monitoring of $\mathrm{NO}_{2}$ concentration in passenger compartments. Results under controlled experimental conditions illustrate the performance of our prototype. Measurements in an urban bus under real driving conditions certify the possibility to use such a microsystem for this purpose.

\section{Experimental}

\subsection{Specific methodology of measurement}


The monitoring of oxidising gases in passenger compartments requires sensors with the best sensing performances, close to ideal ones, such as short response times, high resolution, low threshold, good reproducibility of results, and selectivity. To obtain such performances with phthalocyanine gas sensor devices, we have developed an original methodology of measurement. This method allows us to improve the reproducibility of results obtained and to take no notice of the too long response time these sensors suffer. This methodology optimized for ozone monitoring is detailed in a previous paper [17]. To summarize, the principle of this methodology is based on the quantification of gas concentration by the kinetics of sensor response during short times of exposure, and on cyclic recalibration of sensor by a thermal cleaning process in purified air.

Figure 1 is a schematic representation of temperature, flow and conductivity evolutions during one cycle of our methodology. During the first step, the sensor is maintained at high temperature in clean air. The conductivity firstly increases due to the semiconductor effect and secondly decreases due to the thermal desorption of gaseous species already chemisorbed during the previous cycle. At the end of this step, the sensitive layer is "regenerated". During the second step, the sensor is still maintained in pure air but at lower working temperature. The conductivity decreases due to the annihilation of intrinsic charge carriers by the negative temperature gradient. At the end of this second stage, the initial conductivity $\sigma_{i}$ is stabilized and measured. The third and last step corresponds to the exposure of the sensor to polluted air for a short time at low working temperature. Sensor conductivity slowly increases due to the creation of extrinsic charge carriers in the sensitive material by charge transfer between the oxidising chemisorbed gaseous molecules and the reduced phthalocyanine molecular units. Interaction mechanisms between gases and this molecular semiconductor will be explained later. At the end of the cycle, the final conductivity under gas $\sigma_{\mathrm{f}}$ is measured and a new cycle begins. The sensor response is thus defined as $\left(\sigma_{\mathrm{f}}-\sigma_{\mathrm{i}}\right)$. Obviously, responses and even 
performances are a function of delays and temperatures of each cycle. Optimization of all these working conditions will be discussed in the section 3.2 .

\subsection{Gas sensor microsystem}

The complete microsystem constituted by the sensitive element, the fluid circuit and the electronic peripheral devices is represented by Fig. 2 . The sensor is constituted by a thin film of copper phthalocyanine, this organic molecular semiconductor being judicious for this application because of its insensitivity to reducing gases which induces a partial selectivity to the structure. The layers are realized by thermal sublimation under secondary vacuum $\left(\mathrm{P}=10^{-6}\right.$ mbar) of copper phthalocyanine powder commercialized by Kodak. An automatic deposition control system (Model ADS-220 from Veeco) associated with a quartz oscillator regulates the deposition rate and controls the deposited thickness. This layer thickness is $300 \mathrm{~nm}$ and the deposition rate is maintained at $0.2 \mathrm{~nm} / \mathrm{s}$ to achieve homogenous layers. During the process, the substrates are maintained at room temperature and no consecutive post-deposition thermal annealing is realized. Thus, the $\mathrm{CuPc}$ layers obtained are amorphous and exhibit better sensing characteristics than crystalline ones [18-21]. Sensitive thin layers are deposited onto interdigitated electrodes with accurate dimensions, screen-printed on the upper side of alumina substrates to determine their electronic conductivity. On the lower side, a screenprinted platinum resistor, with a predefined thermal coefficient, is used to regulate the sensor temperature during experiments. The dimensions of the sensing element are $3 \mathrm{~mm} \times 5 \mathrm{~mm}$.

The sensor structure is polarized under $5 \mathrm{~V}$ d.c. and a data acquisition system (Model 2000 or 2700 , Keithley) records a voltage as a function of the electric current passing through the sensitive layer, image itself of copper phthalocyanine conductivity. The conversion of current into voltage is realized by means of an electronic converter with adjustable gain. The structure temperature is controlled by a temperature regulator which can commute between two values by an external control signal. 
To avoid gas adsorption on the inner walls, the measuring cell and the fluid circuit are realized in PTFE. Moreover, an exhaust pump sets the flow to $750 \mathrm{ml} / \mathrm{min}$ and is located downstream from the cell to avoid adding interfering species in the sensor environment. The commutation between polluted air and purified air is made by means of a PTFE solenoid valve, the purified air being obtained by an air flow through an active charcoal cartridge. At the sampling input, a dust filter can be added especially during experimental tests under real conditions. The solenoid valve, the temperature regulator and the data acquisition system are synchronously driven by a self-contained microcontroller unit developed at laboratory. Moreover, as microsystem performances are related to delays of each step and period, these parameters can be modified by experimenters in this unit. The best working conditions are argued in the following.

\subsection{Infrastructure for tests under real conditions}

After calibration under artificially polluted atmosphere in laboratory, this microsystem has been put in a bus of the network of Clermont-Ferrand (France) to realize on-board measurements and thus to validate this prototype. The experimental vehicle was a Heuliez GX 317 Compressed Natural Gas bus. The bus route is from the suburb of Clermont-Ferrand to the downtown, near the railway station district. The length of its route is approximately 7.6 $\mathrm{km}$ and the common delay of the journey for normal traffic conditions is approximately 40 min. The microsystem has been placed on the seat just behind the bus driver and the sampling input has been maintained at the respiratory level of passengers. During experiment, only the bus driver and four experimenters were present in the passenger compartment. To be in the same conditions as usual, the bus opens, waits for a few seconds and then closes its gates in the front of each bus stop. After each measurement, the global position of the bus is noted to correlate the concentration of pollutants deducted from microsystem response with traffic conditions and the nearest fixed station of air quality control.

\section{Results}




\subsection{Target gas and interfering species: preliminary study}

Nitrogen dioxide is a major pollutant of urban atmosphere but coexists with a few other gaseous species such as nitrogen monoxide, carbon monoxide, sulphur dioxide, ozone, volatile organic compounds (VOCs) and heavy metals. So, efficient $\mathrm{NO}_{2}$ monitoring requires drastically selective gas sensors. Copper phthalocyanine is a molecule well-known to be highly reactive with oxidising gases and insensitive to reducing ones. So, phthalocyanine thin film conductivity is not very modified by carbon monoxide $(\mathrm{CO})$ and nitrogen monoxide (NO). With sulphur dioxide $\left(\mathrm{SO}_{2}\right)$, none of previously published work has reported even a low reactivity with $\mathrm{CuPc}$. Moreover, the development of electronuclear energy and the decrease in fuel sulphur rate have greatly contributed to the decrease in $\mathrm{SO}_{2}$ concentration in atmosphere since several years, levels becoming very low. Electronic charge transfer between phthalocyanine and heavy metals being impossible, no conductivity variation can be correlated with heavy metals concentration variations. For VOCs and hydrocarbons, no response correlated with these compounds has been observed during previous experiments realized on phthalocyanine gas sensors. So, in our experimental context, ozone can be considered as the main interfering gas.

Preliminary measurements have been made to compare $\mathrm{NO}_{2}$ and $\mathrm{O}_{3}$ rates in vehicles moving on urban streets. An experimental vehicle equipped with two commercial gas analyzers (ultraviolet photometric ozone analyzer, model 49i, Thermo Electron Corporation, and chemiluminescent nitrogen oxides analyzer, model 42i, Thermo Electron Corporation) parked in the downtown of Clermont-Ferrand (140000 inhabitants; population density: 3200 inhab $/ \mathrm{km}^{2}$ ) near a high density traffic road and close to one monitoring station of the regional air quality control network is used to measure in-vehicle oxidising pollution as a function to ambient air pollution. $\mathrm{NO}_{2}$ and $\mathrm{O}_{3}$ concentrations are recorded every $5 \mathrm{~min}$ in vehicle and compared to the data of the fixed station delivered every $15 \mathrm{~min}$. Moreover, to reproduce bus 
working conditions, i.e. cyclic gate opening/closing sequence, outdoor atmospheric air is injected in vehicle each hour during $10 \mathrm{~min}$ by means of an electric fan.

Figures 3 and 4 represent respectively $\mathrm{NO}_{2}$ and $\mathrm{O}_{3}$ concentration variations during two days measured by commercial analyzers, in the vehicle (thin line) and simultaneously in ambient atmosphere by the nearest air quality control station (thick line). Although concentration variation magnitudes are in the same order for these two oxidising gases in outdoor atmosphere, in-vehicle concentration variations are strongly different. Figures show that the average concentration of $\mathrm{NO}_{2}$ remaining into the vehicle after $50 \mathrm{~min}$ of confinement is nine times higher than this relative to ozone. Ozone concentration remains very small (1 to $2 \mathrm{ppb})$ whatever the outdoor level. At the same time, $\mathrm{NO}_{2}$ concentration depends from outdoor level. Moreover, for the same outdoor levels, the quantity of $\mathrm{NO}_{2}$ in vehicle during the $10 \mathrm{~min}$ of air admission is higher than for $\mathrm{O}_{3}$. Ozone is quickly and completely decomposed in passenger compartments whereas nitrogen dioxide remains the predominant oxidising gas. Such a phenomenon has been already quantified $[5,10,15]$.

If passenger compartments contribute to the dissociation of ozone, traffic density near the vehicle is another parameter leading to the same tendency. Indeed, in urban areas, a high proportion of nitrogen oxides are ejected by fuel engines as NO [22]. But, ozone reacts very easily with nitric oxide to produce nitrogen dioxide in accordance with the reaction:

$$
\mathrm{NO}+\mathrm{O}_{3} \leftrightarrows \mathrm{NO}_{2}+\mathrm{O}_{2}
$$

So, in traffic, $\mathrm{O}_{3}$ is non-existent and $\mathrm{NO}_{2}$ is the only oxidising gas.

As mentioned above, phthalocyanine-based gas sensors exhibit a partial selectivity towards oxidising species. Moreover, under our experimental conditions, i.e. vehicles moving on urban streets, ozone is quickly decomposed into nitrogen dioxide by nitrogen monoxide. So, the response of our gas sensor microsystem will be only correlated with the variations of invehicle nitrogen dioxide rate.

\subsection{Sensor response under $\mathrm{NO}_{2}$ : optimization of working conditions}


Interaction processes between oxidising gases and phthalocyanine molecular units have been identified and discussed in previous papers [23,24]. The first equilibrium involves physical sorption of oxidising molecules, competitive sorption with pre-adsorbed species and diffusion into the bulk of the layer. Consecutively, gaseous molecules can be chemisorbed to form negative ions and extrinsic charge carriers are created (holes) into the molecular semiconductor by charge transfer process. These charge carriers can be delocalized onto the other phthalocyanine molecular units of the layer leading to electronic conductivity by hopping process. Thus, interaction of oxidising molecules on phthalocyanine leads to the creation of holes at the surface and into the bulk, inducing the increase in thin layer electronic conductivity. Nevertheless, if interaction processes seem similar for ozone and nitrogen dioxide, sensor responses are different because of the lower stability of $\mathrm{O}_{3}{ }^{-}$anions as compared to $\mathrm{NO}_{2}^{-}$.

Consequently, if the working conditions have been optimized for the monitoring of $\mathrm{O}_{3}$ in atmosphere [24], some parameters must be improved for the efficient measurement of $\mathrm{NO}_{2}$. As mentioned above, nitrogen dioxide anions $\mathrm{NO}_{2}^{-}$being more chemically stable than $\mathrm{O}_{3}{ }^{-}$ species, desorption from the sensitive layer is more difficult and slower. So, to improve sensor cleaning just before pollutant exposure and to avoid the lack of reproducibility due to the irreversible part of chemisorbed species accumulation into the sensitive layer, the delay and the temperature of the thermal cleaning phase have been increased. However, for cleaning temperature above $180^{\circ} \mathrm{C}$, we observe an irreversible decrease in microsystem sensor response even if $\mathrm{NO}_{2}$ concentration remains constant. This drift can be explained by an irreversible hot oxidation of phthalocyanine molecules by chemisorbed $\mathrm{NO}_{2}$ ones in material leading progressively to the deterioration of the sensitive thin layer. The time of the cycle is maintained to $15 \mathrm{~min}$, this one corresponding to the period of measurement chosen by the national air quality control network. During this short delay, the evolution of pollutants is very slow and concentration variations remain very small. That justifies the detection of 
nitrogen dioxide in real time by our microsystem. Moreover, phthalocyanine gas sensors exhibiting very high sensitivities to oxidising gases, conductivity variations for short times of exposure remain high. Thus, the optimized working conditions for $\mathrm{NO}_{2}$ are as follows: lower temperature $($ detection $)=80^{\circ} \mathrm{C}$, higher temperature $=180^{\circ} \mathrm{C}$, sensor regeneration time $\left(\mathrm{t}_{0}\right)=$ $12 \mathrm{~min}$, sensor stabilization time $\left(\mathrm{t}_{1}\right)=1 \mathrm{~min}$, sensor exposure time $\left(\mathrm{t}_{2}\right)=2 \mathrm{~min}$, cycle period $=15 \min$.

To illustrate gas sensor microsystem performances, Fig. 5 represents sensor microsystem response versus nitrogen dioxide concentration in the range 0-100 ppb, a common range of urban atmosphere. Experiment has been made for monotone increasing $(\mathbf{O})$ and monotone decreasing $(\bigcirc)$ concentrations, with a concentration variation step equal to $10 \mathrm{ppb}$. Moreover, for each $\mathrm{NO}_{2}$ concentration, 4 consecutive measurements are realized. Results show that measurements are efficient and satisfying for all the concentrations of the range studied. The threshold of detection is very low and can be estimated to be a few ppb (approximately 2-3 $\mathrm{ppb}$ ). The sensitivity is also high. The ratio is exactly the same between sensor microsystem response in $\mathrm{mV}$ and gas concentration in $\mathrm{ppb}$ (response is multiplied by 2 when gas concentration is twice). Moreover, the coefficient of proportionality between microsystem response and $\mathrm{NO}_{2}$ concentration is $1 \mathrm{mV}$ for $20 \mathrm{ppb}$ with a signal/noise ratio very important. For a monotone gas concentration variation, the reproducibility is excellent as illustrated by the superimposition of experimental points. Nevertheless, when $\mathrm{NO}_{2}$ rate firstly increases and secondly decreases, a weak hysteresis phenomenon occurs: responses are higher for increasing concentrations than for decreasing ones. This induces particularly that the response to $60 \mathrm{ppb}$ of $\mathrm{NO}_{2}$ in increasing concentration is the same as that response to $50 \mathrm{ppb}$ in decreasing one. Consequently, the microsystem resolution is lower than 20 ppb but remains greater than $10 \mathrm{ppb}$.

If the previous experiment is well adapted to quantify sensing characteristics, the fidelity of the microsystem for high concentration gradients cannot be determined. To estimate the 
reproducibility even for fast and high concentration variations of $\mathrm{NO}_{2}$ (artificial pollution peaks), experiment has been realized with different concentration gradients. Figure 6 represents the gas sensor microsystem response under optimized working conditions versus the time for various exposure sequences to $\mathrm{NO}_{2}$ in the range 0-100 ppb. Microsystem responses $\left(\mathcal{O}\right.$, scale on the left) are delivered every $15 \mathrm{~min}$ and compared to the $\mathrm{NO}_{2}$ concentration $(O$, scale on the right) measured by a commercial gas analyzer. For each concentration, 6 points of measurements are recorded. These results strengthen the low threshold, high sensitivity, and good reproducibility of successive measurements already emphasized by previous figure. For $\mathrm{NO}_{2}$ concentrations between 0 and $80 \mathrm{ppb}$ with a $20 \mathrm{ppb}$ variation step, no common values are obtained for two different concentrations. The resolution is still $<20 \mathrm{ppb}$ in this range. However, when the concentration quickly increases from $20 \mathrm{ppb}$ to $100 \mathrm{ppb}$, we can observe a slow increase in sensor response, a few values being similar to ones relative to $80 \mathrm{ppb}$. The stabilization of response in this case is slow and the accuracy of measurement is altered. This effect is not noticeable for fast decreases. The gas sensor microsystem response can be influenced by previous exposures but so fast $\mathrm{NO}_{2}$ level variations are not often observed in rural or urban atmosphere. Thus, as illustrated by results obtained at laboratory, the working conditions mentioned above are the best ones for $\mathrm{NO}_{2}$ monitoring in urban atmosphere.

\subsection{Microsystem response variation law versus gas concentration: calibration curve}

The main objective of this study being the continuous monitoring of $\mathrm{NO}_{2}$ in air and not only the detection of thresholds, it is necessary to determine the relation between the microsystem response and the corresponding nitrogen dioxide concentration to inform drivers and passengers about the quantities they breathe in. To establish this variation law, a calibration curve has been realized with a $10 \mathrm{ppb}$ concentration step. Figure 7 represents the response to $\mathrm{NO}_{2}$ delivered by the gas sensor microsystem in the range 0-100 ppb. For each concentration 6 successive measurements have been made. The gain of the electronic current- 
voltage converter has been increased (multiplied by 200 as compared to Fig. 6) to obtain signal easily measurable by a simple voltmeter or available for signal treatment units, still with a high signal/noise ratio. In the first approximation, we could consider that the response is proportional to $\mathrm{NO}_{2}$ concentration with a coefficient of proportionality to $0.012 \mathrm{~V}$ per ppb. By applying a simple linear regression to the experimental points, the determination coefficient, also named regression coefficient, $\mathrm{R}^{2}=0.9931, \mathrm{R}^{2}$ being $=1$ for a perfect correlation between a mathematical model and experimental points. Nevertheless, the best determination coefficient is obtained for a polynomial regression. Indeed, for $\mathrm{Y}=3 \times 10^{-5} \mathrm{X}^{2}+$ $0.0098 \mathrm{X}$, the determination coefficient is $\mathrm{R}^{2}=0.9992$. So, the variation laws are as follows:

$$
\text { response }=\mathrm{a}\left[\mathrm{NO}_{2}\right]^{2}+\mathrm{b}\left[\mathrm{NO}_{2}\right](2)
$$

or inversely:

$$
\left[\mathrm{NO}_{2}\right]=\left(-\mathrm{b}+\sqrt{\mathrm{b}^{2}+4 \text { aresponse }}\right) / 2 \mathrm{a}
$$

with $\mathrm{a}=3 \times 10^{-5} ; \mathrm{b}=9.8 \times 10^{-3} ;\left[\mathrm{NO}_{2}\right]$ in ppb and response in $\mathrm{V}$.

This last equation will be the mathematical relation giving the nitrogen dioxide concentration near the sensitive thin layer and the gas sensor microsystem response during experiments under real conditions.

\subsection{Results in urban context}

Results obtained at laboratory are confirmed under real using conditions by the implementation of this microsystem in a bus of the local bus network in Clermont-Ferrand, according to the conditions mentioned in section 2.3 .

The results are illustrated in Fig. 8 which represents the $\mathrm{NO}_{2}$ concentration variations in ppb deducted from the calibration curve of our microsystem versus the date and hour of the measurement. The variations are between 30 and $60 \mathrm{ppb}$, the middle of the gas concentration range studied. No specific trend is noticeable as a function of morning or afternoon. We can only observe that the higher concentrations appear at the beginning of afternoon. 
The $\mathrm{NO}_{2}$ level in urban areas strongly depends on traffic density [1], the localization of vehicles in the city at the moment of measurement (downtown, suburb or industrial zone) [4] and driving conditions (flowing traffic, traffic jam, numerous traffic lights) [22]. These experimental details are essential for the best interpretation of results. Table 1 gives the local hour of measurement points, the nitrogen dioxide concentration deducted from the microsystem calibration curve, the localization of bus at the same time (road type) and the ambient $\mathrm{NO}_{2}$ concentration delivered by the nearest station of air quality control network by means of a commercial chemiluminescent analyzer. We can notice from the table data that the lowest $\mathrm{NO}_{2}$ concentrations have been recorded when the bus is parked on the campus where the traffic is lower. Nitrogen dioxide being essentially an automotive pollutant, its concentration is higher when the traffic is more important. Experimental results confirm this trend. Moreover, the higher concentrations are recorded in urban roads just after lunch. This increase could be explained by the rise in traffic due to the more important number of commuters driving from their houses or from restaurants to their work offices.

By comparison between $\mathrm{NO}_{2}$ concentrations measured in passenger compartments and in ambient air by the nearest stations of pollutant monitoring, it is noticeable that all in-vehicle values are higher than those delivered by fixed stations. This seems to confirm that monitoring stations underestimate the real exposure of drivers and bus users to $\mathrm{NO}_{2}$ because of their distance from driving ways.

To summarize, the satisfying results obtained under real conditions emphasize the strong correlation of urban $\mathrm{NO}_{2}$ with traffic density and seems to confirm that the real exposure of drivers and commuters must be efficiently evaluated by an-board gas sensor microsystem.

\subsection{Selectivity of gas sensor microsystem: discussion}

As we have previously mentioned in this article, copper phthalocyanine thin layers exhibit a strong chemical reactivity with strong oxidising gases such as $\mathrm{NO}_{2}$ and $\mathrm{O}_{3}$, which confers a partial selectivity to gas sensors using this semiconductor as a sensitive material. Moreover, 
under such real experimental conditions (in passenger compartments, on high traffic density, in urban areas), ozone levels are negligible and even zero as compared to $\mathrm{NO}_{2}$ concentration. So, under such working conditions, the gas sensor microsystem is drastically selective for nitrogen dioxide.

Nevertheless, we have demonstrated in previous works that for the same concentrations, the methodology of measurements provides higher sensor responses to $\mathrm{O}_{3}$ than $\mathrm{NO}_{2}$, and even makes the sensor selective for ozone [24]. Consequently, the gas sensor microsystem is selective for nitrogen dioxide only if ozone concentration remains equal to zero. The selective monitoring of $\mathrm{NO}_{2}$ is not achieved especially if a bus is driving in the suburbs or in rural areas where with fair climatic conditions, ozone rates are often more important.

To reach the drastic selectivity for nitrogen dioxide under all conditions, one solution consists in removing completely ozone in the sensor environment, whatever ambient concentration, without changing nitrogen dioxide concentration. This can be realized by means of a selective gas filter. Amongst all the material investigated we can mention manganese dioxide $\mathrm{MnO}_{2}$, active charcoal, fullerene $\mathrm{C}_{60}$, stainless steel cuttings and indigo. Only indigo can be considered as a real selective ozone filter. Experimental results on the filtering power of indigo powder towards $\mathrm{NO}_{2}$ and $\mathrm{O}_{3}$ are illustrated in Table 2. In the concentration ranges studied, $\mathrm{O}_{3}$ is entirely eliminated and $\mathrm{NO}_{2}$ preserved. Moreover, indigo powder being easily sublimed under vacuum to be deposited onto substrates and being insulating, this material is really suitable for the realization of an integrated selective ozone filter on semiconductor based sensors. Thus, the selectivity for $\mathrm{NO}_{2}$ will be obtained by the implementation of an indigo filter in our microsystem. Two solutions could be considered: either by inserting an indigo cartridge in the fluid circuit, in the parallel fluid line of this set with an active charcoal cartridge (in Fig. 1, purified air = air without any pollutant and polluted air = air without ozone), or by using a phthalocyanine gas sensor with an integrated indigo filtering layer. The first very promising results obtained with this kind of structure will 
be the subject of a next paper.

\section{Conclusion}

The implementation of an on-board gas sensor microsystem is essential to determine the real exposure of drivers and passengers to $\mathrm{NO}_{2}$ inside vehicles. After preliminary studies which establish that nitrogen dioxide is the only one oxidising species in vehicle passenger compartments, ozone being too unstable and quickly decomposed, we have optimized an original methodology to monitor $\mathrm{NO}_{2}$ in real time by means of phthalocyanine-based gas sensors. This methodology allows determining gas concentration from the kinetics of sensor response during a short time of exposure. Working conditions such as temperatures and delays used are optimized for $\mathrm{NO}_{2}$ as illustrated by experimental results. The high sensitivity, the high resolution $(<20 \mathrm{ppb})$, the low threshold (few ppb), the good reproducibility, and the real time detection obtained are in accordance with specifications relative to this application.

The variation law of microsystem response with $\mathrm{NO}_{2}$ concentration is determined with accuracy and the calibration curve established. Measurements under real conditions, i.e. in an urban bus passenger compartment with usual driving conditions (cyclic gate opening/closing sequence) exhibit the possibility and the reliability of $\mathrm{NO}_{2}$ monitoring by means of this microsystem, the results confirming the trends already reported. The results obtained clearly show the strong influence of traffic density on the sensor microsystem response. Moreover, the results highlight that the $\mathrm{NO}_{2}$ concentrations deduced from in-vehicle measurements are always higher than those determined by the nearest fixed monitoring station of the local air quality control network. Ozone can be considered as the main interfering gas for the monitoring of $\mathrm{NO}_{2}$ in urban atmosphere. This microsystem being sensitive to strong oxidising gases, the real selectivity for nitrogen dioxide will be achieved by removing ozone in the sensor environment. A way of improvement is finally proposed, especially using a real selective $\mathrm{O}_{3}$ chemical filter added in the fluid circuit or integrated on sensor sensitive layers. 
Acknowledgements: Special thanks are given to the local air quality control network AtMO AUVERGNE for its help, the commercial analyzers lending and data from fixed stations of pollution monitoring. This research was supported by the mix association of transport of Clermont-Ferrand (SMTC) in the context of the EnviroBus project.

\section{Biographies}

J. Brunet received his Ph.D. degree from Université Blaise Pascal, France, in 2003, for his research on the prospect of gas-sensing properties of semiconductors, and especially for the development and optimization of phthalocyanines-based gas sensors, devoted to the evaluation of pollutant concentrations in the atmosphere. Since 2004 , he has been working at the LASMEA as an Associate Professor. His research is now devoted to efficient gas sensor microsystems and to the development of integrated filtering layers on sensors to reach a drastic selectivity.

A. Pauly, Professor at the Blaise Pascal University, received his HDR in 2002 for his research in the field of gas sensors. He is presently the Head of the Gas Sensors group in the LASMEA, with research interests in organic and inorganic sensitive materials, and the development of gas sensors microsystem.

C. Varenne received her Ph.D. degree from Université Blaise Pascal, France, in 1996 for the development and the modelling of electrical characteristics of structures based on semiconductor III-V. Presently she works at this university as an Associate Professor. She is involved in projects about the development of gas sensors based on III-V and molecular semiconductors. 
B. Lauron started his career in the department of production process machinery engineering from "Michelin tyre manufacturing company - France". He received his Engineer Degree in industrial automatism from the "Conservatoire National des Arts et Métiers" (CNAM), Paris, France in 1986. In 1987, he received the M.S. Degree in electronics and systems from Université* Blaise PASCAL (UBP), Clermont-Ferrand, France. Currently, he is with the "Centre National de la Recherche Scientifique" (CNRS) as a Research Engineer in material science. After focusing his attention to electrical characterization methods about inorganic and molecular semiconductors, his current topic of interest includes the study of gas/material interfaces for the development of gas sensors. 


\section{References}

[1] L. Y. Chan, H. W. Y. Wu, A study of bus commuter and pedestrian exposure to traffic air pollution in Hong Kong, Environ. Int. 19 (1993) 121-132.

[2] G. Barrefors, G. Petersson, Exposure to volatile hydrocarbons in commuter trains and diesels buses, Environ. Technol. 17 (1996) 643-647.

[3] S. Kingham, J. Meaton, A. Sheard, O. Lawrenson, Assessment of exposure to trafficrelated fumes during the journey to work, Transpn. Res.-D 3 (1998) 271-274.

[4] J. H. V. Wijnen, A. P. Verhoeff, H. W. A. Jans, M. V. Bruggen, The exposure of cyclists, car drivers and pedestrians to traffic-related air pollutants, Int. Arch. Occup. Environ. Health 67 (1995) 187-193.

[5] T. R. Johnson, Recent advances in the estimation of population exposure to mobile source pollutants, J. Expo. Anal. Environ. Epidemiol. 5 (1995) 551-571.

[6] L. Y. Chan, C. Y. Chan, Y. Qin, The effect of commuting microenvironment on commuter exposures to vehicular emission in Hong Kong, Atmos. Environ. 33 (1999) 1777-1787.

[7] J. E. Gómez-Perales, R. N. Colvile, A. A. Fernández-Bremauntz, V. Gutiérrez-Avedoy, V. H. Páramo-Figueroa, S. Blanco-Jiménez, E. Bueno-López, R. Bernabé-Cabanillas, F. Mandujano, M. Hidalgo-Navarro, M. J. Nieuwenhuijsen, Bus, minibus, metro intercomparison of commuter's exposure to air pollution in Mexico City, Atmos. Environ. 41 (2007) 890-901.

[8] A. T. Chan, Commuter exposures and indoor-outdoor relationships of carbon oxides in buses in Hong Kong, Atmos. Environ. 37 (2003) 3809-3815.

[9] A. A. Fernandez-Bremauntz, M. R. Ashmore, Exposure of commuters to carbon monoxide in Mexico City - I. Measurements of in-vehicle concentrations, Atmos. Environ. 29 (1995) 525-532.

[10] C. C. Chan, H. Ozkaynak, J. D. Spengler, L. Sheldon, Driver exposure to Volatile Organic Compounds, $\mathrm{CO}$, Ozone and $\mathrm{NO}_{2}$ under different driving conditions, Environ. Sci. Technol. 25 (1991) 964-972.

[11] O. Hertel, P. Wilhard, R. Berkowicz, H. Skov, Exposure of bus drivers and postmen to air pollution from traffic in their working environment, J. Aerosol Sci. 28 (1997) 1102.

[12] J.C. Limasset, F. Diebold, G. Hubert, Assessment of bus driver's exposure to the pollutants of urban traffic, Sci. Total Environ. 134 (1993) 39-49.

[13] B. Son, W. Yang, P. Breysse, T. Chung, Y. Lee, Estimation of occupational and nonoccupational nitrogen dioxide exposure for Korean taxi drivers using microenvironmental model, Environ. Res. 94 (2004) 291-296.

[14] S. Saenghirunvattana, W. Wananukul, C. Mokkhavesa, N. Opasi, Increasing carbon monoxide blood levels in Bangkok bus drivers, Environ. Int. 21 (1995) 81-84. 
[15] International Center for Technology Assessment, "In-Car Air Pollution: The Hidden Threat to Automobile Drivers: Report No. 4, An Assessment of the Air Quality Inside Automobile Passenger Compartments," July 2000.

[16] F. Palmgren, R. Berkowicz, O. Hertel, E. Vignati, Effects of reduction of $\mathrm{NO}_{\mathrm{X}}$ on the $\mathrm{NO}_{2}$ levels in urban streets, Sci. Total Environ. 189/190 (1996) 409-415.

[17] J. Brunet, J.P. Germain, A. Pauly, B. Lauron, C. Varenne, A methodology of measurements for phthalocyanine gas sensors dedicated to the detection of ozone and nitrogen dioxide. Results in urban air pollution context, Sensors for Environmental Control, World Scientific Publishing (2003), 188-192.

[18] G.E. Collins, J.W. Pankow, C. Odeon, R. Brina, C. Arbour, J-P. Dodelet, Thin film sensors : the role of defects and impurity sites in controlling sensor response and selectivity, J. Vac. Sci. Technol. A 11 (1993) 1383-1391.

[19] M. Masui, M. Sasahara, T. Wada, M. Takeuchi, Gas sensitive properties of copper phthalocyanine thin films, Appl. Surf. Sci. 92 (1996) 643-646.

[20] J.C. Hsieh, C.J. Liu, Y.H. Ju, Response characteristics of lead phthalocyanine gas sensor: effects of film thickness and crystal morphology, Thin Solid Films 322 (1998) 98-103.

[21] Y-L. Lee, W-C Tsai, C-H Chang, Y-M. Yang, Effects of heat annealing on the film characteristics and gas sensing properties of substituted and un-substituted copper phthalocyanine films, Appl. Surf. Sci. 172 (2001) 191-199.

[22] D. C. Carslaw, S. D. Beevers, Development of an urban inventory for road transport emissions of $\mathrm{NO}_{2}$ and comparison with estimates derived from ambient measurements, Atmos. Environ. 39 (2005) 2049-2059.

[23] M. Passard, A. Pauly, J.P. Blanc, S. Dogo, J.P. Germain, C.Maleysson, Doping mechanisms of phthalocyanines by oxidizing gases: Application to gas sensors, Thin Solid Films 237 (1994) 272-276.

[24] J. Brunet, A. Pauly, L. Mazet, J.P. Germain, M. Bouvet, B. Malezieux, Improvement in real time detection and selectivity of phthalocyanine gas sensors dedicated to oxidizing pollutants evaluation, Thin Solid Films 490 (2005) 28-35. 


\section{Figure captions}

Fig. 1: Schematic representation of the methodology of measurement developed for phthalocyanine-based gas sensors. Upper part: chronograms relative to flow and temperature sequential changes; lower part: conductivity variations of a phthalocyanine thin layer during three steps and definition of gas sensor microsystem response.

Fig. 2: Self-contained gas sensor microsystem for real time monitoring of oxidising gases in atmosphere.

Fig. 3: Comparison between $\mathrm{NO}_{2}$ concentration variations in ppb measured by commercial chemiluminescent $\mathrm{NO}_{\mathrm{X}}$ analyzer in a car passenger compartment (-) to those recorded at the same time by an analyzer of the nearest station of air quality control network AtMO AUVERGNE (-) during 2 days. To reproduce the gate opening/closing sequence of urban buses, outdoor atmosphere is injected by means of an electric fan during 10 min each hour.

Fig. 4: Comparison between $\mathrm{O}_{3}$ concentration variations in ppb measured by commercial UV photometric $\mathrm{O}_{3}$ analyzer in a car passenger compartment (-) to those recorded at the same time by an analyzer of the nearest station of air quality control network AtMO AUVERGNE (一) during 2 days. In vehicle, outdoor air is injected by means of an electric fan each hour during $10 \mathrm{~min}$ to reproduce the gate opening/closing sequence of urban buses.

Fig. 5: Gas sensor microsystem response versus $\mathrm{NO}_{2}$ concentration in the range $0-100 \mathrm{ppb}$. Results have been obtained for monotone increasing $(\bigcirc)$ and decreasing $(\bigcirc)$ concentrations with 4 points of measurement for each concentration. 
Fig. 6: Gas sensor microsystem response $(\mathbf{O})$ for various $\mathrm{NO}_{2}$ concentrations monitored by a commercial $\mathrm{NO}_{\mathrm{X}}$ analyzer $(\mathrm{O})$ in the range 0-100 ppb. For each concentration, 6 consecutive measurements are realized.

Fig. 7: Calibration curve of the gas sensor microsystem under $\mathrm{NO}_{2}$ in the concentration range 0-100 ppb. For each concentration, 6 consecutive measurements are realized. The variation law between microsystem response and gas concentration is established from these results.

Fig. 8: $\mathrm{NO}_{2}$ concentration variations in a bus passenger compartment for common driving conditions measured by on-board microsystem and deducted from the calibration curve represented on figure 7. 


\section{Table captions}

Table1: Experimental conditions for measurements in a bus passenger compartment represented in Fig. 8. Simultaneously listed are the local hour of measurement recorded, the $\mathrm{NO}_{2}$ concentration extracted from microsystem response and calibration curve, road type and $\mathrm{NO}_{2}$ concentration of the nearest station of air quality control network, AtMO AUVERGNE.

Table 2: Quantification of the filtering power of indigo towards ozone and nitrogen dioxide. Efficiency is defined as the percentage of $\mathrm{O}_{3}$ or $\mathrm{NO}_{2}$ removed by indigo powder in the concentration ranges of those measured in urban atmosphere. 


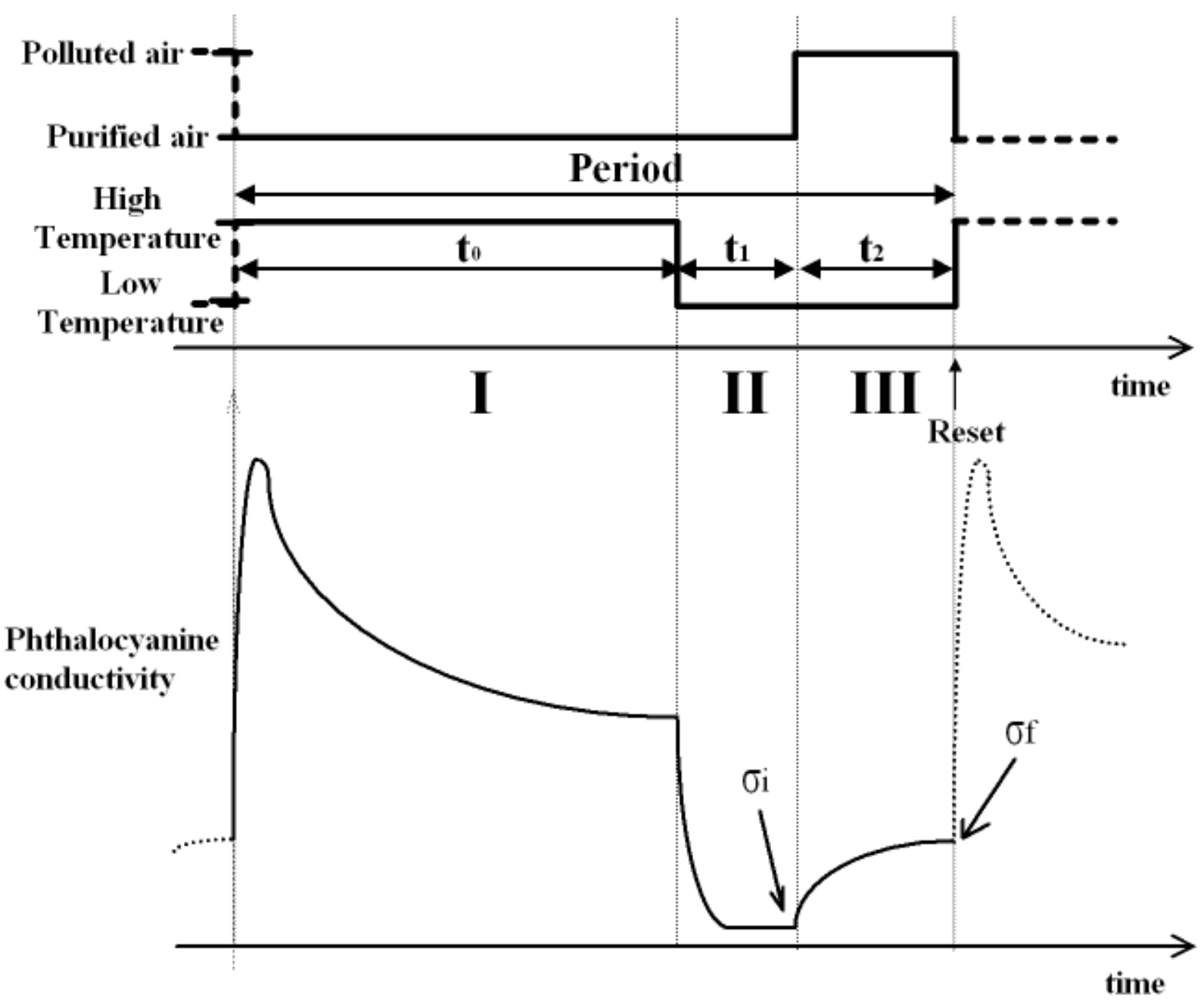

Fig. 1 


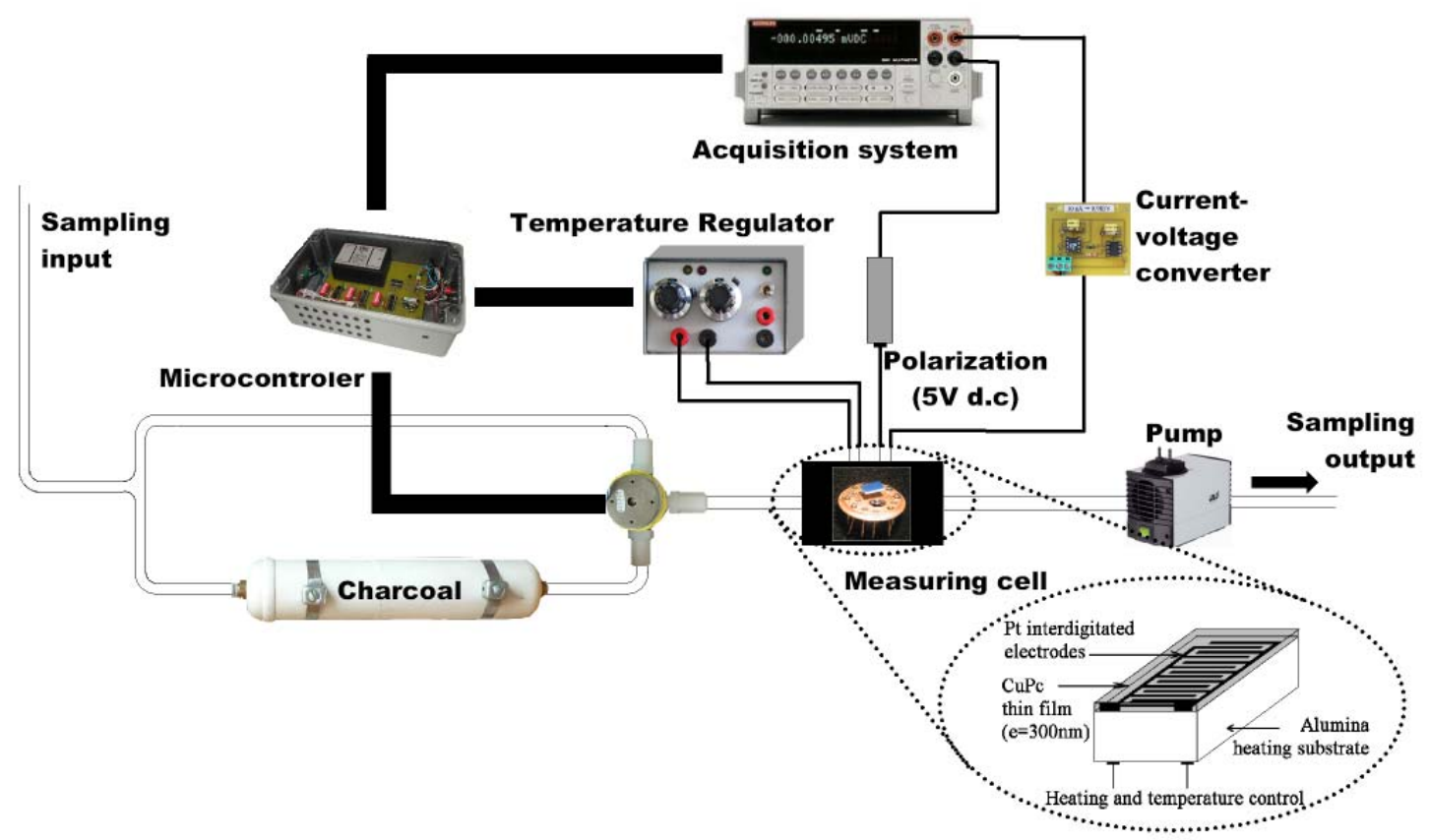

Fig. 2 


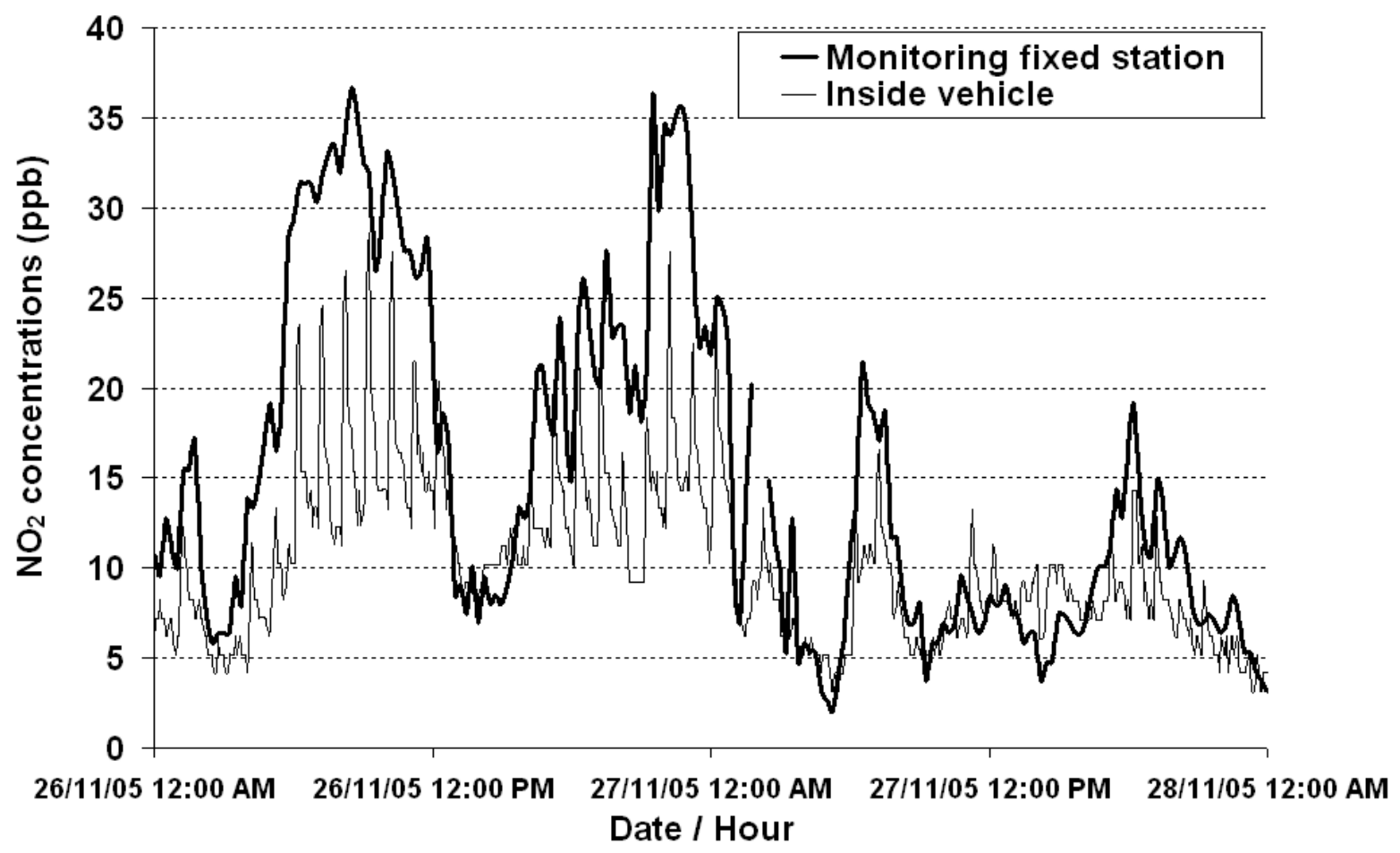

Fig. 3 


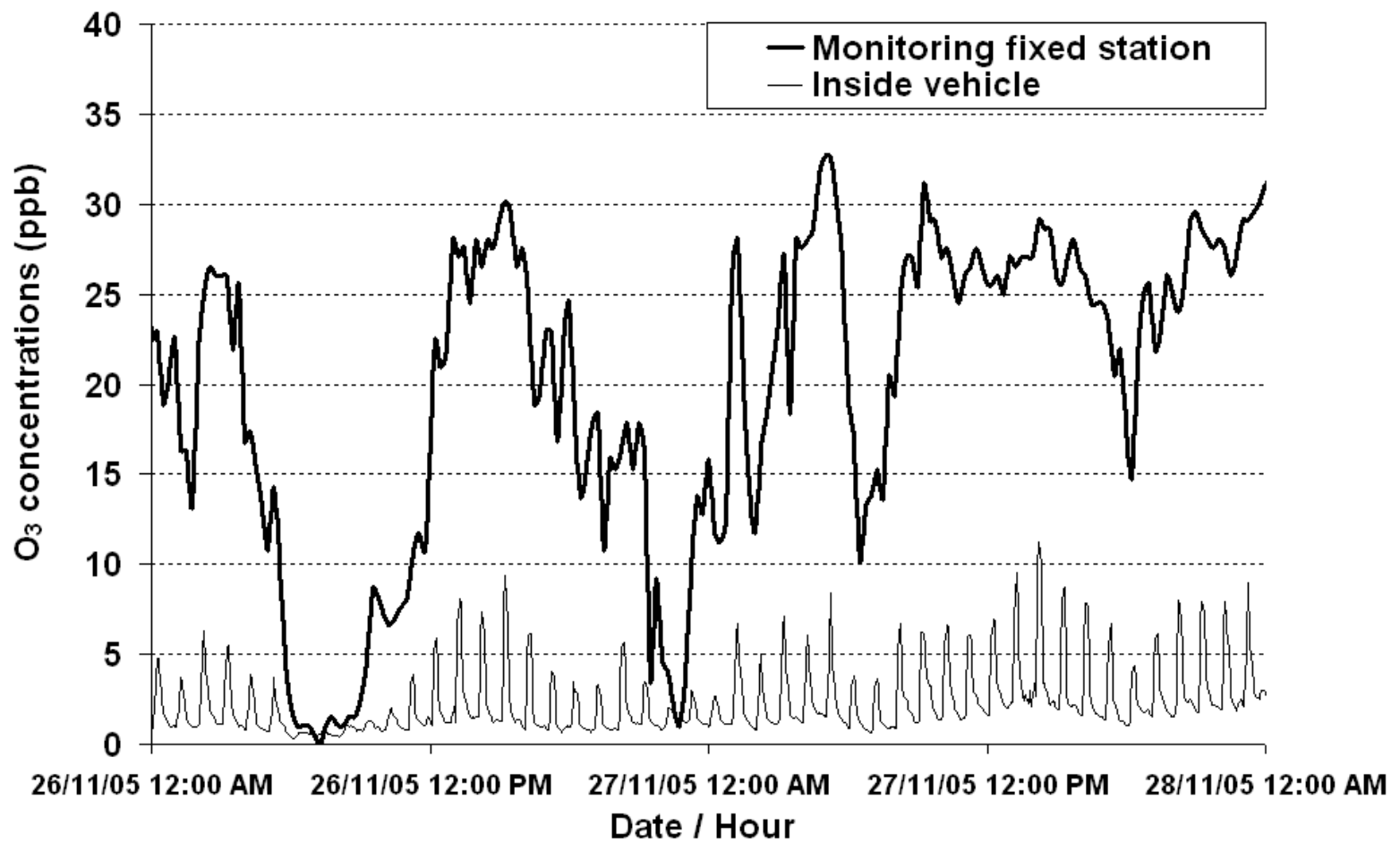

Fig. 4 


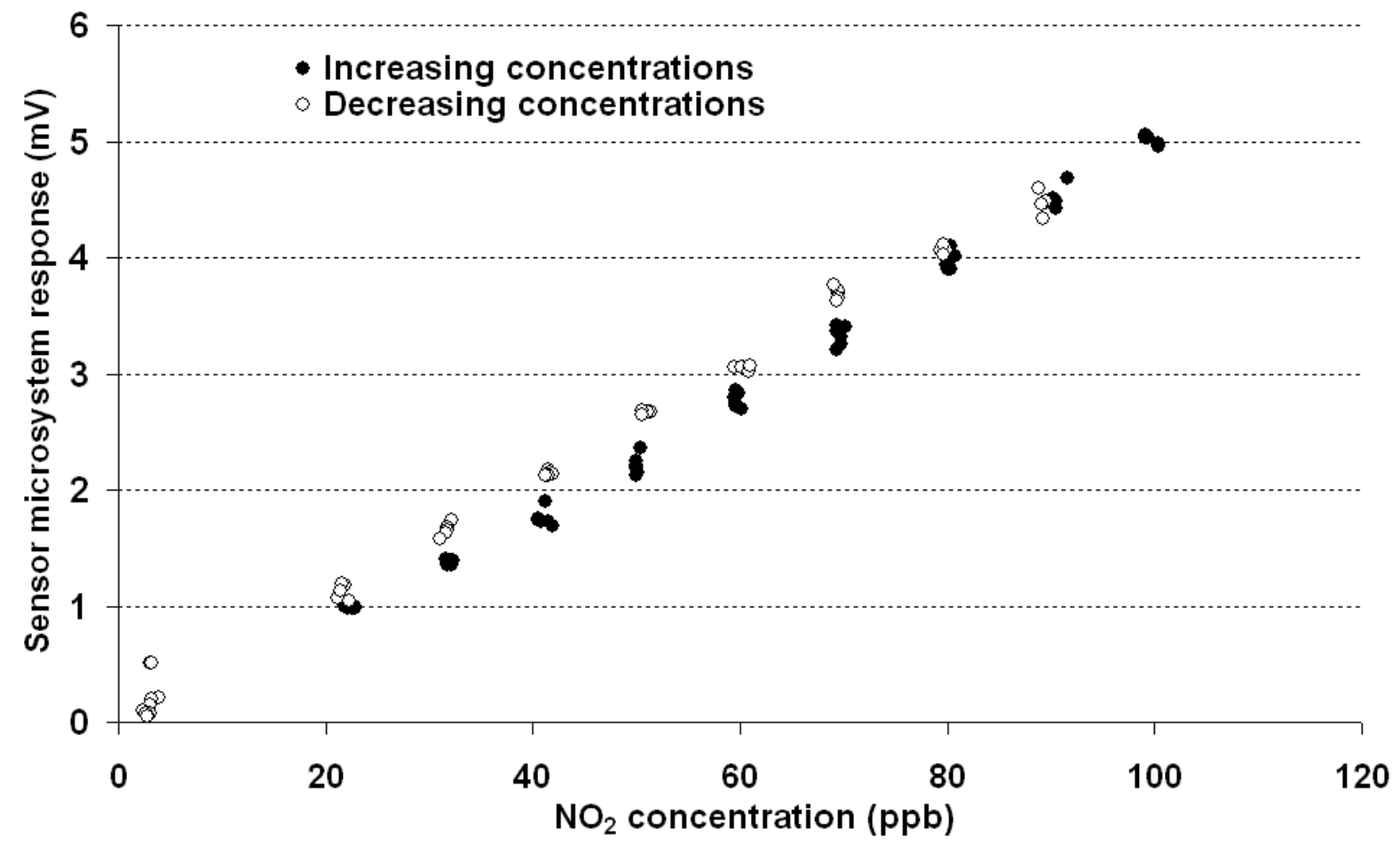

Fig. 5 


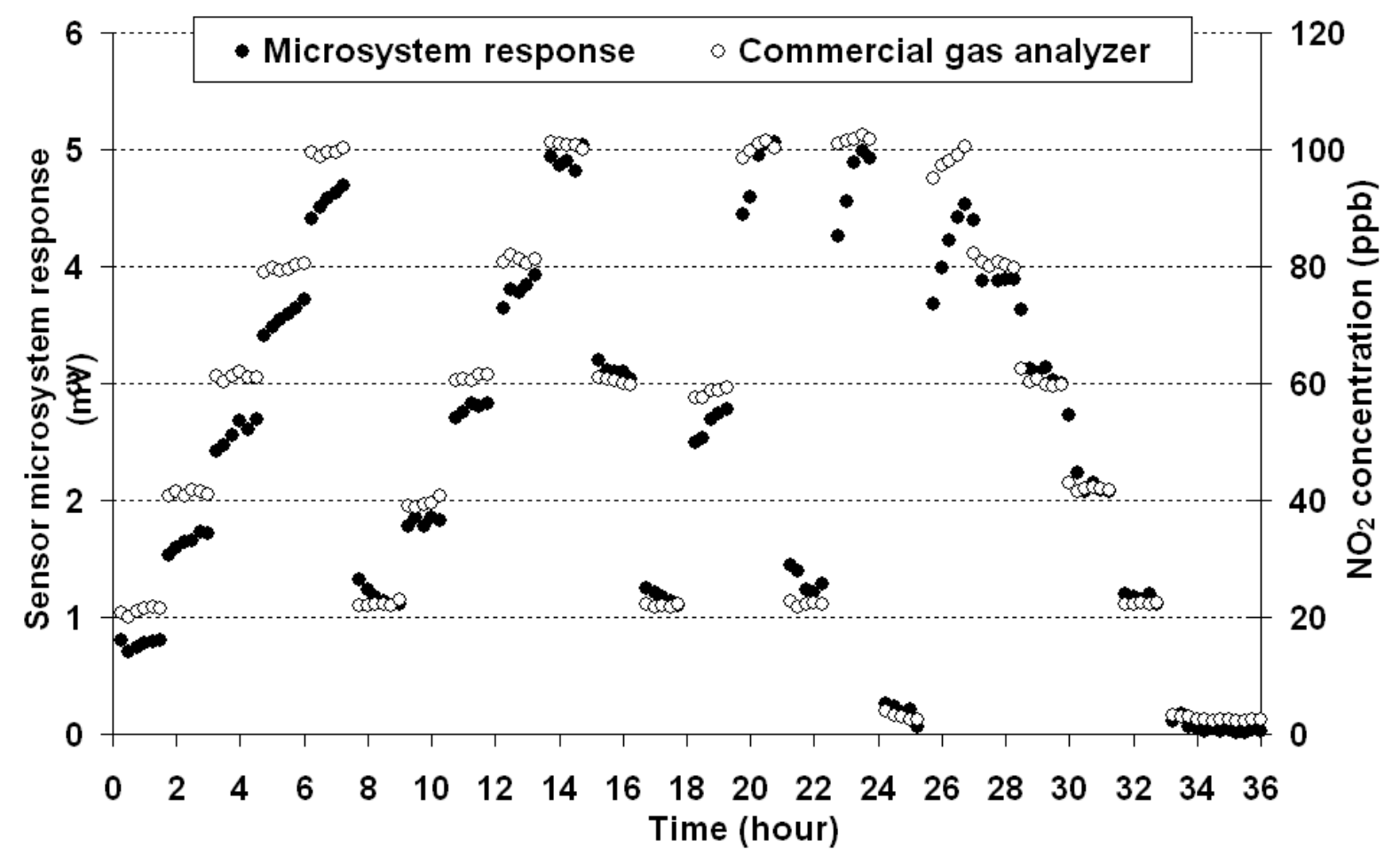

Fig. 6 


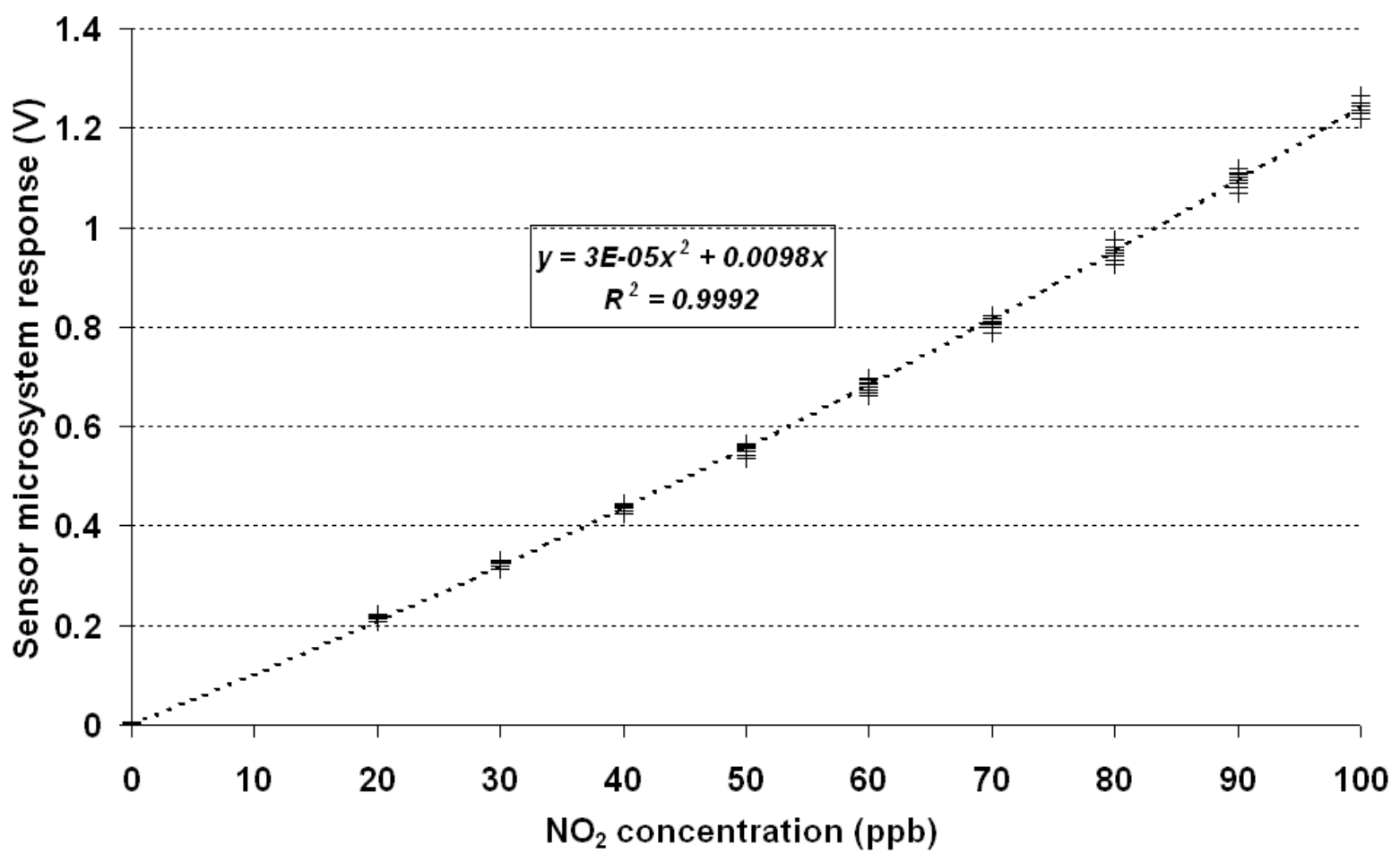

Fig. 7 


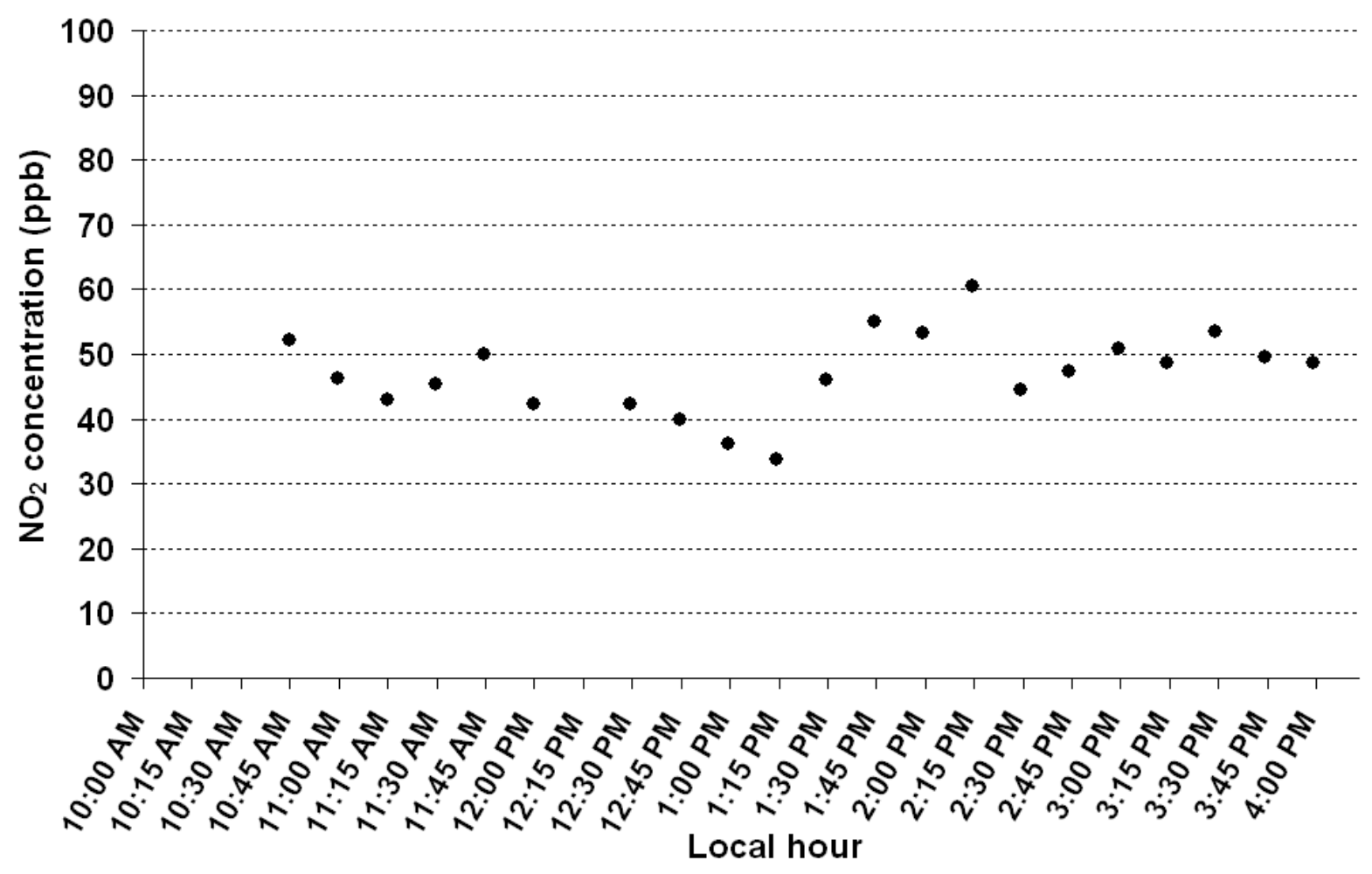

Fig. 8 


\begin{tabular}{|c|c|c|c|}
\hline Local hour ${ }^{a}$ & $\begin{array}{c}\mathrm{NO}_{2} \text { measured } \\
(\mathbf{p p b})^{\mathbf{b}}\end{array}$ & Road type & Nearest station $(p p b)^{\circ}$ \\
\hline $10: 45 \mathrm{AM}$ & 52 & Urban & 11 \\
\hline $11: 00 \mathrm{AM}$ & 46 & Suburb & n.a. ${ }^{d}$ \\
\hline $11: 15 A M$ & 43 & Urban & n.a. ${ }^{d}$ \\
\hline $11: 30 \mathrm{AM}$ & 45 & Urban & 25 \\
\hline $11: 45 \mathrm{AM}$ & 50 & Urban & 16 \\
\hline $12: 00 \mathrm{PM}$ & 42 & Campus & 10 \\
\hline $12: 15 P M$ & - & Campus & 10 \\
\hline $12: 30 P M$ & 42 & Campus & 10 \\
\hline $12: 45 P M$ & 40 & Campus & 10 \\
\hline $1: 00 P M$ & 36 & Campus & 10 \\
\hline $1: 15 P M$ & 34 & Campus & 10 \\
\hline $1: 30 P M$ & 46 & Urban & 12 \\
\hline $1: 45 P M$ & 55 & Urban & 8 \\
\hline 2:00 PM & 53 & Urban & 8 \\
\hline $2: 15 P M$ & 61 & Urban & $n . a^{d}$ \\
\hline $2: 30 P M$ & 44 & Campus & 22 \\
\hline $2: 45 P M$ & 47 & Urban & $n . a^{d}$ \\
\hline $3: 00 P M$ & 51 & Urban & 10 \\
\hline $3: 15 P M$ & 49 & Urban & 10 \\
\hline $3: 30 P M$ & 54 & Urban & 13 \\
\hline $3: 45 P M$ & 50 & Suburb & n.a. ${ }^{d}$ \\
\hline 4:00 PM & 49 & Suburb & n.a. ${ }^{d}$ \\
\hline \multicolumn{4}{|c|}{ a During experiments, local hour is defined as Universal Time +2 hours } \\
\hline \multicolumn{4}{|c|}{${ }^{b} \mathrm{NO}_{2}$ concentrations are deducted from calibration curve of sensor microsystem } \\
\hline \multicolumn{4}{|c|}{$\begin{array}{l}\text { ' } \mathrm{NO}_{2} \text { concentrations of the nearest air quality monitoring stations are delivered by the } \\
\text { local network of air quality control AtMO AUVERGNE }\end{array}$} \\
\hline \multicolumn{4}{|c|}{ n.a.: not available } \\
\hline
\end{tabular}

Table 1 


\begin{tabular}{|c|c|c|}
\hline \multicolumn{2}{|c|}{$\mathrm{NO}_{2}$ concentration (ppb) } & \\
\hline Upstream from indigo filter & Downstream from indigo filter & Efficiency \\
\hline 17 & 7 & $59 \%$ \\
\hline 21 & 16 & $24 \%$ \\
\hline 37 & 35 & $5 \%$ \\
\hline 53 & 51 & $4 \%$ \\
\hline 70 & 68 & $3 \%$ \\
\hline \multicolumn{3}{|c|}{$\mathrm{O}_{3}$ concentration (pph) } \\
\hline Upstream from indigo filter & Downstream from indigo filter & Efficiency \\
\hline 73 & 1 & $99 \%$ \\
\hline 92 & 1 & $99 \%$ \\
\hline 105 & 1 & $99 \%$ \\
\hline 125 & 1 & $99 \%$ \\
\hline 137 & 1 & $99 \%$ \\
\hline
\end{tabular}

Table 2 